\title{
A relação entre a estrutura de propriedade e o custo da dívida captada via emissão de debêntures no Brasil
}

\author{
Jonatan Marlon Konraht \\ https://orcid.org/0000-0001-6586-6583｜Ｅ-mail: jonatan.konraht@iffr.edu.br \\ Silvia Consoni \\ https://orcid.org/0000-0002-3967-7006 | E-mail: silviaconsoni@yahoo.com.br
}

Marcos Wagner da Fonseca

https://orcid.org/0000-0002-9804-6271 | E-mail:mwfonseca@ufpr.br

\section{Resumo}

Objetivo: Esta pesquisa teve como objetivo identificar a relação entre o percentual de participação direta na propriedade (controle) e o custo da captação de dívida via emissão de debêntures no Brasil.

Método: O custo da dívida (spread da taxa de juros das emissões de debêntures) foi regredido com a estrutura de propriedade (concentração de propriedade direta, concentração de controle direto e excesso de controle) usando regressões lineares e quadráticas para o período de 2011 a 2018.

Resultados: Os resultados encontrados sugerem que, entre as características de estrutura de propriedade/ controle analisadas, somente a concentração de controle direto é relevante para os debenturistas no momento da precificação dos títulos.

Contribuições: A pesquisa contribui à literatura ao evidenciar que a relação entre concentração de controle e spread é quadrática. Assim, até certo ponto, o aumento da concentração de controle se reflete no aumento do custo da dívida; porém, quando essa concentração se torna muito elevada, os credores a interpretam como algo benéfico, reduzindo o custo da dívida. Tais resultados sugerem que os efeitos positivos e negativos decorrentes da concentração de controle estão presentes na captação de dívida; porém, os benefícios tendem a se manifestar apenas quando a concentração de controle se torna elevada. Palavras-Chave: Custo da dívida. Custos da Emissão de Debêntures. Custos de Agência. Estrutura de Propriedade. Concentração Acionária. 


\section{Introdução}

O capital de terceiros representa uma fonte significativa de recursos alocados para investimentos nas empresas, mesmo para aquelas de capital aberto. As empresas latino-americanas, por exemplo, têm níveis de dívida semelhantes aos das empresas dos Estados Unidos da América, apesar de experimentarem benefícios fiscais relativamente menores, maiores custos de falência e acesso restrito a diversas fontes de financiamento, principalmente de longo prazo (Céspedes, González, \& Molina, 2010).

A literatura em finanças reconhece que existem potenciais conflitos sempre que proprietários e credores divergirem em suas respectivas funções de utilidade, preferências de risco e informações (Jensen, 1986; Jensen \& Meckling, 1976; Myers, 1977). Apesar disso, os principais mecanismos de governança corporativa são, a priori, projetados para promover o alinhamento de interesses entre proprietários e administradores e, até mesmo, entre proprietários (Shleifer \& Vishny, 1997). No entanto, , há motivos para acreditar que certos mecanismos de governança corporativa possam ser avaliados desfavoravelmente pelos detentores de títulos de dívida, em específico, a configuração da propriedade (Ashbaugh-Skaife, Collins, \& LaFond, 2006; Jiraporn, Chintrakarn, Kim, \& Liu, 2013).

Existem esforços de pesquisa no sentido de considerar o efeito da estrutura de propriedade, enquanto mecanismo de governança corporativa, no custo da dívida. Os esforços se concentram, predominantemente, na análise de empresas dos Estados Unidos da América, da Europa e da Ásia, conforme constatado na revisão da literatura. Em geral, as empresas listadas na bolsa de valores brasileira apresentam particularidades de estrutura de propriedade em relação às empresas de propriedade difusa do modelo convencional de controle corporativo dos Estados Unidos da América e do Reino Unido como elevada concentração de propriedade (controle) e baixa contestabilidade do poder do acionista dominante (Crisóstomo, Brandão, \& López-Iturriaga, 2020), além do exercício do controle corporativo ser consistentemente preservado pela emissão de ações de dupla classe e por estruturas piramidais (Aldrighi, 2014; Aldrighi \& Mazzer Neto, 2007; Aldrighi \& Postali, 2011; Bortolon, 2013). Por conseguinte, há uma distribuição desigual do poder de controle que pode levar o proprietário dominante a exercer forte influência na definição da política de investimento, entre outras consequências, de forma a atender a seus interesses pessoais em detrimento dos interesses dos demais acionistas (Bebchuk, Kraakman, \& Triantis, 2000; Claessens, Djankov, Fan, \& Lang, 2002; La Porta, Lopez-de-Silanes, Shleifer, \& Vishny, 2000).

Para abordar o efeito da estrutura de propriedade no custo da dívida no mercado de capitais brasileiro, o objetivo traçado busca identificar a relação entre o percentual de participação direta na propriedade (controle) e o custo da captação de dívida via emissão de debêntures no Brasil. Para caracterizar o efeito pontual de um mecanismo específico de governança corporativa sobre o custo da dívida, as debêntures são consideradas como uma modalidade específica de captação de dívida, com potencial de gerar conflitos de interesses entre proprietários e credores. A pesquisa possui relevância nesse contexto, pois a emissão de debêntures pode ser considerada uma das principais modalidades de financiamento de longo prazo disponíveis para as companhias brasileiras, inclusive se comparadas às emissões de ações. Segundo dados do Boletim de Mercado de Capitais 02/2020, da Associação Brasileira das Entidades dos Mercados Financeiro e de Capitais (Anbima), as emissões de debêntures realizadas entre os anos de 2014 e 2019 somaram aproximadamente $\mathrm{R} \$ 626$ bilhões, enquanto a captação de recursos via emissões de ações (Ofertas Públicas Iniciais e follow-ons) somou aproximadamente $\mathrm{R} \$ 185$ bilhões (ANBIMA, 2020). 
Em contraste com pesquisas precedentes sobre o custo da dívida no Brasil (p.e. Fonseca \& Silvera, 2016; Konraht, Camargo, \& Vicente, 2016; Barros, Silva, \& Voese, 2015), o spread da taxa de juros das debêntures não apresenta os potenciais problemas presentes na proxy de custo da dívida quando determinada pela razão entre despesas financeiras e passivo oneroso. As despesas financeiras compreendem os juros e, ainda, outros encargos financeiros como variações monetárias e cambiais suportados pelas empresas não só na captação de empréstimos e financiamentos, mas aqueles relativos aos prazos de pagamento firmados com fornecedores em geral e os descontos concedidos, por exemplo. Além disso, o passivo oneroso pode ser influenciado pelo volume de dívida que as empresas captam ou amortizam em períodos próximos ao período de reporte, o que insere ruídos na mensuração do custo da dívida.

Os resultados obtidos sugerem que, entre as características da estrutura de propriedade direta consideradas na análise (concentração de propriedade direta, concentração de controle direto e excesso de controle), somente o percentual de concentração de controle direto (direitos de voto) mostrou ser relevante aos credores no momento da precificação das debêntures. A existência de uma relação quadrática entre concentração de controle e o spread da taxa de juros de captação de dívida via emissão de debêntures sugere que a concentração de controle aumenta o custo da dívida e à medida que esta concentração de controle se torna excessivamente elevada o custo da dívida tende a diminuir. Esta redução no spread insinua que os credores podem estar considerando a concentração de controle como um fator que potencialmente reduz o risco de ocorrer troca de controle ao longo da vigência do contrato de dívida.

O efeito da estrutura de propriedade sobre o valor da empresa, na perspectiva dos credores, mostra-se como um ponto controverso na literatura de governança corporativa, pois na perspectiva dos credores, quanto maior a concentração de controle menor o retorno exigido. Conjectura-se, por isso, que a concentração de controle estaria sendo associada a menor a probabilidade de troca da gestão da empresa e das suas políticas financeiras durante a vigência do contrato de dívida. Ou seja, a concentração de controle representaria aos credores a manutenção dos níveis de risco e do cumprimento dos covenants contratuais após a concessão do crédito.

A análise dos resultados apresentados é entendida como um indício do comportamento dos credores na precificação de debêntures no Brasil e precisa ser avaliada com cautela, pois, para identificar a estrutura de propriedade foram utilizados apenas os percentuais de participação diretos do(s) proprietário(s) indicado(s) como controlador(es) quando da divulgação da estrutura de propriedade pela empresa. Desde 2005 é possível perceber que, no mercado de capitais brasileiro, ocorreu uma redução na emissão de ações de dupla classe enquanto as estruturas indiretas de controle têm aumentado (Andrade, Bressan, \& Iquiapaza, 2014; Bortolon \& Leal, 2014). Apesar da relevância de estruturas de controle indiretas no mercado de capitais brasileiro, obter o percentual de propriedade do acionista último não é uma das tarefas mais fáceis, nem mesmo indicar se a propriedade é detida por uma família. Parte do desafio refere-se à presença de empresas não listadas em bolsa de valores nas estruturas piramidais e ao tempo necessário de coleta. Além disso, pesquisas têm mostrado que o percentual de participação direta do proprietário dominante se proxima do percentual de participação indireta do acionista último, ressalvadas especifidades de amostra e período abrangido (Aldrighi, 2014; Bortolon, 2013, Grillo, Reina, Bortolon, \& Sarlo Neto, 2017). Estas e outras limitações de execução deste estudo sinalizam que há desdobramentos a serem explorados em pesquisas futuras que melhor possam definir os contornos do efeito relatado. 


\section{Revisão da literatura e desenvolvimento das hipóteses}

O uso de capital de terceiros favorece o compartilhamento do risco dos investimentos com os credores. Neste ponto, o excesso de investimento (overinvestment), o subinvestimento (underinvestment) e o esvaziamento da propriedade podem explicar certos custos de agência da dívida. A adoção de projetos de investimentos não lucrativos (substituição de ativos) ou excessivamente arriscados (risk-shifting) aumentam a variância dos fluxos de caixa futuros da firma e transferem aos credores desproporcionalmente os resultados negativos que possam ser obtidos (Jensen, 1986; Jensen \& Meckling, 1976). Da mesma forma, projetos de investimento de valor presente líquido positivo podem ser rejeitados se os lucros residuais forem preferencialmente transferidos aos credores, caracterizando o problema de subinvestimento (Myers, 1977), inclusive, se o pagamento de dividendos for preferível. Em todas estas circunstâncias se estaria alterando o risco de não recebimento das reinvindicações contratuais fixadas pelos credores, principalmente se o endividamento se tornar relativamente alto, situação na qual os esforços dos insiders em controlar o risco de restrição financeira, falência e de liquidação será supostamente bastante reduzido (Jensen, 1986, Aslan \& Kumar, 2012).

Os credores, à medida que preveem a existência desses custos de agência, certamente exigem taxas de juros maiores e fazem constar nos contratos de dívida cláusulas restritivas para reivindicar garantias adequadas e impor mecanismos de monitoramento do uso dos recursos cedidos. Sob este argumento, é concebível que não exista uma relação significativa entre a estrutura de propriedade (controle) e o custo da dívida. Contudo, nem sempre se pode tratar de todas as contingências futuras ou, ainda, encontrar soluções pouco onerosas para o monitoramento de investimentos em projetos de valor presente líquido negativo (Steijvers \& Vooerdeckers, 2009). Por conseguinte, o custo da dívida tende a aumentar à medida que os conflitos de interesses entre insiders e credores aumentam ou não possam ser remediados (Aslan \& Kumar, 2012).

Sanchez-Ballesta e García-Meca (2011) avaliaram a influência da concentração de propriedade e da identidade dos proprietários no custo da dívida em uma amostra de empresas espanholas entre os anos de 1999-2002. Os resultados relatados sinalizam efeito significativo restrito à propriedade detida pelo presidente do conselho, pelo governo e pelos bancos. Em geral, a identidade do proprietário parece ter contribuído para a redução do custo da dívida, enquanto a concentração de propriedade não se mostrou estatisticamente relevante. Lugo (2019) apresenta evidências empíricas sobre o custo da dívida de empréstimos bancários entre 1996 e 2010 de empresas de diversos países da Europa, Ásia e também dos Estados Unidos da América. O principal resultado apresentado aponta que a participação acionária detita por insiders está inversamente relacionada com o custo da dívida, assumindo a forma de U invertido.

No contexto brasileiro, pouco se sabe sobre a relação exclusiva entre estrutura de propriedade e custo da dívida, em parte, porque os resultados das pesquisas são difíceis de conciliar. Barros et al. (2015) observaram que atributos de governança corporativa que compõe um índice de governnaça, exerceu influência negativa no custo da dívida entre 2008 e 2010, enquanto a adoção de níveis diferenciados de listagem em bolsa de valores não apresentou significância estatística. Fonseca e Silveira (2016) verificaram que o custo da dívida tende a ser menor em função do percentual de ações preferenciais emitidas pelas empresas e devido à adoção de níveis diferenciados de listagem em bolsa de valores no período de 2010 a 2014. Mas outras duas proxies de estrutura de propriedade direta (percentual de participação do maior acionista e a diferença entre controle e propriedade do maior acionista) não apresentaram efeito significativo. Silva, Santos e Almeida (2012) constataram que, entre 2005 e 2010, a concentração de controle esteve associada positivamente com as classificações de crédito para debêntures. Konraht et al. (2016) apresentaram evidências de que o excesso de controle exerce influência positiva no custo da dívida entre os anos de 2011 e 2014. 
Na Europa Ocidental e no Leste Asiático, o custo da dívida é significativamente maior quando há divergência entre propriedade e controle (Aslan \& Kumar, 2012, Lin, Ma, Malatesta, \& Xuan, 2011) e, até mesmo, para o custo de capital (Guedhami \& Mishra, 2009). Ainda, em empresas da Europa e da Ásia, como apresentado por Boubakri e Ghouma (2010), a identidade do proprietário também exerce influência, de tal forma que o excesso de controle familiar tem um efeito positivo sobre os spreads dos títulos de dívida e um efeito negativo nos ratings desses títulos. A capacidade de os insiders efetivamente controlarem os recursos corporativos e de se engajarem em atividades que permitem a extração de benefícios privados do controle está positivamente relacionada ao nível de propriedade que eles detêm (Shleifer \& Vishny, 1997). Entretanto, o entrincheiramento dos insiders pode ocorrer devido à divergência entre direitos de propriedade e de controle (excesso de controle). Em muitas empresas brasileiras de capital aberto esta situação é presumível porque o exercício do controle corporativo tem sido consistentemente preservado pela emissão de ações de dupla classe e estruturas piramidais (Aldrighi \& Mazzer Neto, 2007; Aldrighi \& Postali, 2011; Bortolon, 2013). Desta forma, apresenta-se a seguinte hipótese:

H1: A diferença entre direitos de controle e de propriedade (excesso de controle) aumenta o custo da dívida.

Na perspectiva dos detentores de dívida o efeito da estrutura de propriedade sobre o custo da dívida pode ser diferente da perspectiva dos proprietários insiders e outsiders. Os credores podem se importar muito menos com o entrincheiramento de insiders, desde que o valor da empresa seja mantido acima do limite de inadimplência. Ainda, proprietários com grandes participações não diversificadas podem ter incentivos para alocar recursos de forma a preservá-las, ou seja, para evitar a diluição do capital e preservar o exercício do controle corporativo, aumenta-se a probabilidade do uso de capital de terceiros. Em contrapartida, essa relação de dependência fará com que se tornem mais preocupados com a reputação perante o mercado e, por conseguinte, com a necessidade da manutenção das políticas financeiras durante toda a vigência dos contratos de dívida. De certa forma, isto diminui o risco moral suportado pelos credores após a contratação da dívida (Ashbaugh-Skaife et al., 2006; Jiraporn et al., 2013).

A reputação figura também entre os argumentos apresentados por Anderson, Mansi e Reeb (2003). Eles identificaram que nos Estados Unidos da América a concentração de propriedade nas mãos da família fundadora está negativamente associada ao custo da dívida e explicam que o custo da dívida seria menor nestas circunstâncias porque grandes acionistas, incluindo as famílias, tendem a ser não diversificados. Como a família fundadora está mais exposta ao risco idiossincrático tende a apresentar maior preocupação com sua reputação no mercado e, para atingir as expectativas de longo prazo, tendem a evitar projetos excessivamente arriscados.

Jiraporn et al. (2013) avaliaram a relação entre governança corporativa e custo da dívida para uma amostra de empresas dos Estados Unidos da América. Neste caso, a governança corporativa foi representada pelo índice da ISS (The Institutional Shareholder Services) com categorias de padrões de governança e com ênfase no conselho de administração, auditoria, estatuto, remuneração de executivos e diretores, propriedade, entre outras. Os ratings de crédito e o yield spread foram utilizados como medida de custo da dívida. O resultado obtido mostrou que uma governança corporativa forte reduz significativamente os ratings de crédito e aumenta yield spread. Uma possível explicação para o fato é o quão alinhados estão os interesses da administração e dos proprietários. Quanto maior esse alinhamento (governança corporativa forte) maior seria a possibilidade de subinvestimento, enquanto que a alta concentração de controle nas mãos dos administradores (governança corporativa fraca) reduziria a possibilidade de subinvestimento. 
Klock, Mansi e Maxwell (2005) avaliaram o efeito de um índice de governança que contém vários dispositivos anti-takeover e de proteção aos acionistas no custo do financiamento da dívida para uma amostra de empresas dos Estados Unidos da América, abrangendo o período de 1990-2000. As evidências indicam que dispositivos anti-takeover mais rígidos reduzem o custo do financiamento da dívida. Este resultado sugere que em empresas onde há maior dificuldade para destituição da gestão se estaria aumentando a probabilidade de serem avaliadas favoravelmente no mercado de dívida. Esta constatação elucida que, apesar dos dispositivos anti-takeover mais rígidos desfavorecerem os proprietários, uma vez que impõem maior dificuldade para agirem contra a gestão da empresa, os credores tendem a conceber este fato como um aspecto positivo no dimensionamento do retorno e do risco esperado para o provimento de fundos.

Consistente com a conjectura de que os credores avaliam a estrutura de propriedade de um modo bastante particular, Byun, Choi, Hwang e Kim (2013) constataram que as empresas afiliadas a grandes grupos empresariais coreanos apresentaram entre 2001 e 2007 um custo da dívida substancialmente menor do que as empresas independentes. Eles interpretaram que os credores estão dispostos a conceder crédito com menor taxa de juros e outras condições mais favoráveis às empresas afiliadas a um grupo econômico porque estariam percebendo a possibilidade de proteção adicional. De outra forma, os grupos empresariais serviriam como um compromisso crível para resgatar firmas-membro com problemas financeiros (efeito do cosseguro). Considerando o que foi exposto, formula-se da seguinte hipótese:

H2: A concentração propriedade (controle) reduz o custo da dívida.

\section{Procedimentos Metodológicos}

A amostra é composta pelas emissões de debêntures registradas no Brasil, entre os anos de 2011 a 2018, realizadas pelas empresas não financeiras de capital aberto, excluídas as emissões de debêntures incentivadas e aquelas que foram canceladas logo após o anúncio de emissão. O início do recorte temporal em 2011 decorre da disponibilidade de dados, uma vez que os dados referentes à estrutura de controle e propriedade foram coletados do Formulário de Referência do ano anterior à emissão de debênture, e o início da divulgação desse relatório ocorreu em 2010. O fim do recorte temporal em 2018 se deu em função de ser a data-base mais próxima para coleta e tabulação dos dados de estrutura de propriedade, no período de coleta de dados da pesquisa. A exclusão das debêntures incentivadas se deu em função de estes títulos apresentarem isenção de Imposto de Renda sobre a remuneração auferida pelos debenturistas, o que faz com que os juros reais percebidos pelos credores sejam afetados pelo benefício fiscal contido nas debêntures incentivadas. Consequentemente, o spread das debêntures é diferenciado para as debêntures incentivadas. Assim, foram identificadas 730 emissões de debêntures no Sistema Nacional de Debêntures, sendo que $84(11,9 \%)$ são da modalidade emissão aberta ao público em geral (Instrução Normativa CVM n. $\left.{ }^{\circ} 400\right)$ e 643 (88,1\%) são da modalidade de emissão com esforços restritos (Instrução Normativa CVM n. ${ }^{\circ}$ 476). A modalidade aberta ao público em geral é o formato clássico de emissão de debêntures, em que a empresa emite títulos que podem ser adquiridos por qualquer investidor; a modalidade emissão com esforços restritos é ofertada a um grupo limitado de investidores profissionais, totalizando, no máximo, 75 investidores profissionais que recebem a oferta, sendo que apenas 50 deles podem realizar subscrição ou aquisição desses títulos (Comissão de Valores Mobiliários, 2009). Essas 730 debêntures identificadas somaram um total de 980 séries de títulos de dívida, uma vez que cada debênture pode conter mais de uma série.

As séries de debêntures emitidas e mantidas na amostra apresentam vários critérios de cálculo de remuneração, incluindo índice de referência e spread específicos. Na Tabela 1 são apresentados os critérios de remuneração das séries de debêntures analisadas, bem como os índices utilizados como referência. 
Tabela 1

Índices de referência utilizados nas séries de debêntures

\begin{tabular}{cccc}
\hline Índice & $\begin{array}{c}\text { Séries de } \\
\text { debêntures }\end{array}$ & Proporção & $\begin{array}{c}\text { Amostra final analisada: séries com todos os } \\
\text { dados financeiros disponíveis para coleta }\end{array}$ \\
\hline DI + spread $\%$ & 542 & $55,3 \%$ & 361 \\
\hline \% sobre o DI & 311 & $31,7 \%$ & - \\
\hline IPCA + spread $\%$ & 108 & $11,0 \%$ & - \\
\hline Outros (pós) & 5 & $0,5 \%$ & - \\
\hline Sem índice & 4 & $0,4 \%$ & - \\
\hline TJLP & 4 & $0,4 \%$ & - \\
\hline Taxa pré-fixada & 3 & $0,3 \%$ & - \\
\hline Dólar & 1 & $0,1 \%$ & 361 \\
\hline IGP-M & 1 & $0,1 \%$ & - \\
\hline TR & 1 & $0,1 \%$ & \\
\hline Total & 980 & $100 \%$ & \\
\hline
\end{tabular}

Legenda: DI: Depósitos Interfinanceiros; IGP-M: Índice Geral de Preços do Mercado; IPCA: Índice de Preços ao Consumidor Amplo; TR: Taxa Referencial; TJLP: Taxa de Juros de Longo Prazo.

Nota: as 980 séries estão contidas em 730 emissões de debêntures. A data de levantamento destes dados foi 10 de junho de 2019. As séries de debêntures que não possuíam dados financeiros disponíveis para coleta na base de dados Economatica ${ }^{\circledR}$ ou no site da Comissão de Valores Mobiliários para o cálculo das variáveis da pesquisa foram excluídas da amostra. Isso explica a diferença entre as 542 séries identificadas inicialmente e as 361 com todos os dados disponíveis para análise de dados.

Fonte: elaborado pelos autores.

Como cada forma de remuneração possui um spread específico, não é possível comparar o spread de séries que possuem índices diferentes e, tampouco, realizar a análise global das 980 séries de debêntures em um único modelo de regressão. Em função disto, o critério adotado foi o de analisar as séries de debêntures que adotam a remuneração na forma da taxa de depósitos interfinanceiros (DI), mais uma taxa fixa de spread adicional (DI + spread \%). Foi adotado esse critério em função dessa forma de remuneração ter sido a mais utilizada dentre as 980 séries, o que garante maior quantidade de dados para análise, bem como por conta dessas séries serem as mais representativas das debêntures emitidas no Brasil, de acordo com Konraht e Soares (2020). Além destes aspectos, Konraht e Soares (2020) constataram que as debêntures que oferecem remuneração na forma de "IPCA + spread \%" e "spread \% sobre o DI" tendem a apresentar características da dívida ou características da firma diferenciadas das demais modalidades de emissão, o que indica que essas modalidades são escolhidas por empresas que realizam emissões de maior maturidade, tal como é o caso das que remuneram na forma "IPCA + spread \%", ou são emitidas por empresas com maiores opções de crescimento e que oferecem maior quantidade de cláusulas restritivas para proteção aos credores, como é o caso das que remuneram por "spread \% sobre o DI". Assim, a seleção de outras séries poderia levar a um viés de amostragem caso fossem selecionados títulos com características de risco da dívida e da empresa específicas, quando comparadas às séries em geral, como, por exemplo, se selecionar os títulos de dívida de maturidades mais longas ou emitidas por empresas com maiores oportunidades de crescimento. 
Aproximadamente 55\% das séries de debêntures coletadas oferecem a remuneração pela taxa de depósitos interfinanceiros mais uma taxa fixa de spread (DI + spread \%). Assim, o custo da dívida, variável dependente do estudo, será mensurado pela taxa fixa de spread em relação à taxa DI. A taxa fixa de spread utilizada será aquela já ajustada ao resultado do processo de bookbuilding, procedimento similar ao adotado por Sheng e Saito (2005) e Konraht e Soares (2020). As 361 séries de debêntures que integraram a amostra final foram emitidas por 131 empresas. Essas empresas atuam em diversos setores econômicos, sendo que predominam os setores elétrico (27,7\% das séries), locação de automóveis (11,9\% das séries), transporte rodoviário ( $9,7 \%$ das séries), construção residencial (8,9\% das séries) e sistemas de água e saneamento (5,5\% das séries). Estes setores totalizam aproximadamente $64 \%$ dos títulos de dívida da amostra.

Dado que cada emissão de debênture é realizada em uma data específica ao longo dos anos, optouse pela não utilização de dados em painel, em função de que a estrutura dos dados não é sequencial, e que houve casos de empresas que realizaram apenas uma emissão de debênture durante o período amostral, enquanto outras realizaram mais de uma emissão no período; assim, as hipóteses da pesquisa foram testadas usando Mínimos Quadrados Ordinários (MQO) pooled. Na Equação 1 é apresentado o modelo de regressão especificado para a relação testada nesta pesquisa.

$$
\begin{aligned}
\text { Spread }_{i}=\alpha_{i} & +\beta_{1} \text { Estrutura de propriedade }_{i}+\beta_{2} \text { Tamanho }_{i}+\beta_{3} \text { Endividamento }_{i} \\
& +\beta_{4} \text { Rentabilidade }_{i}+\beta_{5} \text { Garantia real }_{i}+\beta_{6} \text { Selic }_{t}+\sum_{k=2011}^{2018} \delta_{k} \text { Ano }_{k}+\varepsilon_{i}
\end{aligned}
$$

$\mathrm{Na}$ Tabela 2 são apresentadas todas as variáveis que compõem o modelo.

Tabela 2

\begin{tabular}{|c|c|c|c|}
\hline Variável & Sinal & Operacionalização & Referência \\
\hline Spread da dívida & & $\begin{array}{l}\text { Logaritmo natural da taxa de juros adicional em } \\
\text { relação à taxa DI. Esta é a proxy para custo da dívida, } \\
\text { variável dependente do modelo }\end{array}$ & Sheng e Saito (2005) \\
\hline $\begin{array}{l}\text { Estrutura de } \\
\text { propriedade direta } \\
\text { a) concentração de } \\
\text { controle direto }\end{array}$ & - & $\begin{array}{l}\text { Percentual de ações ordinárias (ON) detidas pelo(s) } \\
\text { acionista(s) controlador(es) }\end{array}$ & $\begin{array}{l}\text { Caixe e Krauter (2013); } \\
\text { Claessens et al. (2002); } \\
\text { Silveira, Barros e Famá } \\
(2008)\end{array}$ \\
\hline $\begin{array}{l}\text { Estrutura de } \\
\text { propriedade direta } \\
\text { b) concentração de } \\
\text { propriedade direta }\end{array}$ & - & $\begin{array}{l}\text { Razão entre a soma das ações ordinárias (ON) } \\
\text { e preferenciais (PN) detidas pelo(s) acionista(s) } \\
\text { controlador(es) e o total de ações da empresa }\end{array}$ & Autores \\
\hline $\begin{array}{l}\text { Estrutura de } \\
\text { propriedade direta } \\
\text { c) excesso de controle }\end{array}$ & + & $\begin{array}{l}\text { Razão entre concentração de controle direto e } \\
\text { concentração de propriedade direta menos uma } \\
\text { unidade (controle / propriedade - 1) }\end{array}$ & Cronqvist e Nilsson (2003) \\
\hline Tamanho da empresa & - & Logaritmo natural do ativo total & $\begin{array}{l}\text { Boubakri e Ghouna (2010); } \\
\text { Caixe e Krauter (2013) }\end{array}$ \\
\hline Endividamento & + & Razão entre passivo exigível e ativo total & $\begin{array}{l}\text { Boubakri e Ghouna (2010); } \\
\text { Byun et al. (2013); Li et al. } \\
\text { (2011); Lugo (2019) }\end{array}$ \\
\hline Rentabilidade & - & $\begin{array}{l}\text { Razão entre EBITDA acumulado dos quatro trimestres } \\
\text { anteriores ao da emissão das debêntures e o ativo } \\
\text { total }\end{array}$ & $\begin{array}{l}\text { Byun et al. (2013); } \\
\text { Okimura, Silveira e Rocha } \\
\text { (2007); Silveira et al. (2008) }\end{array}$ \\
\hline Garantia real & $+/-$ & $\begin{array}{l}\text { Variável dummy que assume valor } 1 \text { se a debênture } \\
\text { apresentar garantia real e } 0 \text {, caso contrário }\end{array}$ & Byun et al. (2013) \\
\hline Ano de emissão & $+/-$ & Dummies anuais & Autores \\
\hline Selic & + & Taxa Selic anual do período de emissão da debênture & Autores \\
\hline
\end{tabular}

\section{Descrição das variáveis da pesquisa}

Fonte: elaborado pelos autores. 
Conforme exposto na Tabela 2, três aspectos da estrutura de propriedade são considerados: (a) concentração de controle direto; (b) concentração de propriedade direta; e, (c) excesso de controle. Foi considerado como controlador da empresa o proprietário ou grupo de proprietários identificado(s) como controlador(res) da empresa no Formulário de Referência. Quando havia a indicação de mais de um controlador, foi realizada a soma das participações do grupo indicado. Os três aspectos da estrutura de propriedade foram calculados considerando as participações diretas e esta é uma limitação da pesquisa, dado que não leva em consideração as participações indiretas que ocorrem por meio de estruturas piramidais de controle e ações sem direitos a votos. Todavia, comparações entre estas duas formas de mensuração indicam haver relativa similaridade nos valores calculados pelos dois métodos, tal como apresentado em Grillo et al. (2017). Além disso, testes realizados por Silva (2004) indicam que a relação entre as características de concentração de propriedade/controle, medidas de forma direta e indireta, e o valor das empresas é substancialmente a mesma, embora a mensuração das participações indiretas tenha maior poder explicativo.

Além dessas variáveis de estrutura de propriedade, foram inseridas no modelo de regressão outras variáveis que também podem afetar o custo da dívida. Essas variáveis representam características da empresa, das escrituras de debêntures e macroeconômicas, e são as seguintes: (a) tamanho da firma; (b) endividamento; (c) rentabilidade; (d) oferecimento de garantia real na debênture; (e) taxa efetiva Selic no trimestre de emissão de dívida; e, (f) dummies anuais. O tamanho da firma é uma característica que potencialmente pode representar parte do risco dos credores, e espera-se que empresas maiores tenham menor custo da dívida. Em empresas maiores, o risco de inadimplência seria reduzido devido à possibilidade de venda dos ativos, diante de dificuldades financeiras, além do efeito reputação. $\mathrm{O}$ endividamento também é uma variável que representa risco, sendo que empresas mais endividadas tendem a ter maior risco de entrarem em situação de insolvência e atrasar pagamentos aos credores; assim, é esperado que em empresas mais endividadas o custo da dívida seja maior. A rentabilidade é uma medida de solidez econômica da empresa; assim, é esperado que quanto maior seja a rentabilidade da empresa, menor tenda a ser o custo de captação de dívida, dado que empresas mais rentáveis tendem a ter menor probabilidade de enfrentarem dificuldades econômicas e financeiras. A garantia real é um instrumento de proteção aos credores; assim, é esperado que as debêntures que ofereçam garantia real aos credores tenham menor custo da dívida, considerando que os credores passam a ter maior segurança de recuperação do capital fornecido. Por outro lado, evidências indicam que a garantia real pode ser usada como um mecanismo complementar à taxa de juros para proteção aos credores (Bharath, Sunder, \& Sunder, 2008). Nessa perspectiva, é esperado que, em empresas mais arriscadas, o custo da dívida seja maior e, também, que haja maior probabilidade de conter garantia real. Em função desse impasse teórico, a expectativa para o sinal esperado para a variável garantia real é deixada em aberto. A taxa Selic é a taxa básica de juros do Brasil; assim, é esperado que à medida que ela aumente, haja também um aumento nas taxas de juros praticadas nos títulos de dívida corporativa (debêntures). Por fim, as dummies anuais são inseridas nos modelos para controlar efeitos macroeconômicos que ocorreram no Brasil durante o período de análise, e que podem ter impactado nas taxas de juros cobradas das empresas. 


\section{Resultados}

Na Tabela 3 são apresentadas as estatísticas descritivas das variáveis utilizadas na investigação empírica. No Painel A desta tabela consta a distribuição temporal dos títulos de dívida da amostra; no Painel B constam as estatísticas das 361 observações que integraram a amostra da pesquisa; no Painel C são apresentadas as estatísticas da amostra separadas por modalidade de emissão da debênture. Pelos dados do Painel B, constata-se que, em média, o spread da dívida adicional à taxa DI é de 1,89\% a.a. Essa variável se apresenta heterogênea, sendo o mínimo de $0,24 \%$ e o máximo de $10,2 \%$. O porte das empresas é, também, bastante heterogêneo e, em média, corresponde a $\mathrm{R} \$ 8,9$ bilhões. Os ativos totais são preponderantemente financiados por capital de terceiros, com média de $63 \%$, e isto é relativamente homogêneo entre as empresas da amostra.

Tabela 3

\section{Estatísticas descritivas}

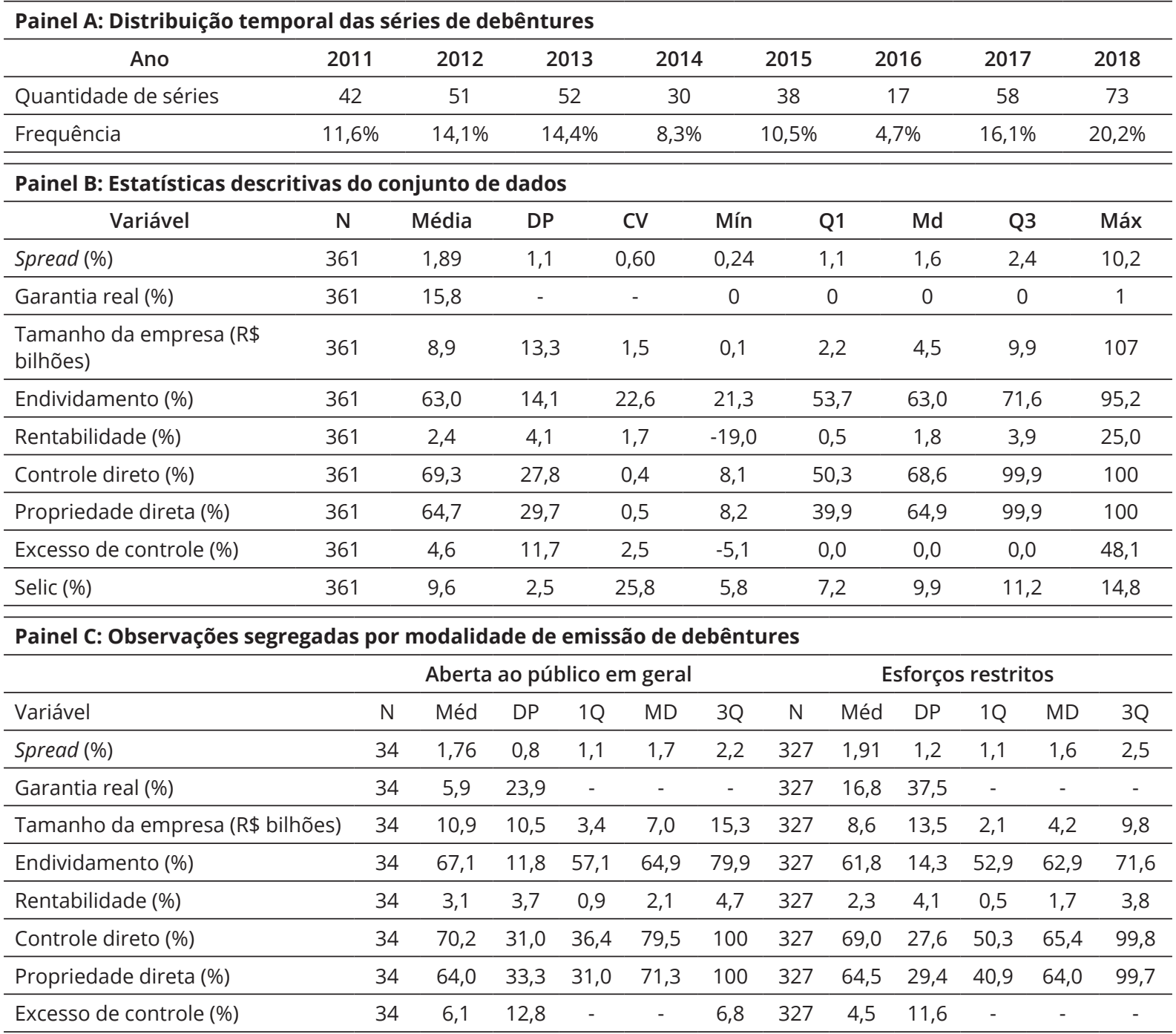

Legenda: N: quantidade de observações; Méd: média; DP: desvio padrão; CV: coeficiente de variação; Mín: menor valor; Q1: primeiro quartil; Md: mediana; Q3: terceiro quartil; Máx: maior valor.

Nota: o total de 361 séries de debêntures apresentadas no Painel B foi emitido por 131 empresas. No Painel C, tem-se que as 34 séries da modalidade aberta ao público em geral foram emitidas por 28 empresas; na modalidade de esforços restritos as 327 séries foram emitidas por 127 empresas. Vinte e quatro empresas emitiram séries das duas modalidades de debêntures.

Fonte: dados da pesquisa. 
$\mathrm{Na}$ amostra há empresas de propriedade e controle pulverizado, e aquelas que são extremamente concentradas, bem como empresas que mantém divergência entre direitos de voto e de fluxo de caixa por meio da emissão de duas classes de ações. Em relação à estrutura de propriedade, observa-se que, em média, a posse de ações com direito a voto é de 69,3\% (min. 8,1\% e máx. 99,9\%) enquanto que, em média, a propriedade detida pelos acionistas controladores é de 64,7\% ( $\min .8,2 \%$ e máx. 99,9\%), valores estes que se assemelham à mediana. A diferença entre controle e propriedade (excesso de controle) é, em média, de 4,6\%, mas bastante heterogêneo entre as empresas. Ademais, ao se analisar a concentração de controle com base nos valores dos quartis, verifica-se que predominam na amostra empresas de controle definido (aproximadamente 75\% da amostra), isto é, que possuem um acionista controlador, o qual possui mais de $50 \%$ das ações com direito a voto. A proporção de direitos de voto está superior, por exemplo, ao descrito em Crisóstomo et al. (2020) que, em média, é de 49\% para o maior acionista, $67 \%$ para os três maiores acionistas e 70\% para os cinco maiores acionistas de amostra de 85 empresas com maior capitalização de mercado no período de 2010 a 2013. As médias de estrutura de propriedade são difíceis de conciliar porque estão sujeitas aos valores extremos da amostra e, até mesmo, a certas especificidades do período compreendido na análise (Andrade et al., 2014; Bortolon \& Leal, 2014). Neste caso específico, apesar de representarem a propriedade direta, não se referem estritamente ao maior acionista e, sim, aos acionistas apontados como controladores, conforme explicitado na seção 3.

Segundo os dados contidos no Painel C, constata-se o predomínio de debêntures emitidas na modalidade esforços restritos, as quais totalizam $90,6 \%$ dos dados da amostra. Tal predomínio pode ser explicado pela maior simplicidade de requisitos exigidos nessa modalidade, o que se reflete em menor custo do processo de emissão. As diferenças médias mais significativas das estatísticas descritivas dessas duas modalidades são que as emissões com esforços restritos fazem maior uso de garantia real como medida de proteção aos credores e tendem a ser emitidas por empresas menores e menos endividadas. No tocante ao custo da dívida, a concentração de controle, de propriedade e o excesso de controle são relativamente similares, embora haja heterogeneidade nas variâncias dessas variáveis entre as duas modalidades.

Os resultados das regressões que tiveram o propósito de identificar o efeito da estrutura de propriedade sobre o custo de captação da dívida via emissão de debêntures no Brasil estão apresentados na Tabela 4. Os três modelos incorporam as características da estrutura de propriedade e apresentaram validade geral ao nível de confiança de $99 \%$, bem como os pressupostos do método de estimação por MQO foram atendidos, indicando que os modelos foram devidamente especificados.

Entre as características de estrutura de propriedade analisadas, somente a concentração de controle direto (Modelo 1) apresentou significância estatística (5\%) e parece ser suficientemente relevante para os credores a ponto de influenciar o custo da dívida. 
Tabela 4

\section{Resultados das estimações por MQO}

Modelo:

Spread $_{i}=\alpha_{i}+\beta_{1}$ Estrutura de propriedade $_{i}+\beta_{2}$ Tamanho $_{i}+\beta_{3}$ Endividamento $_{i}+\beta_{4}$ Rentabilidade $_{i}+\beta_{5}$ Garantia real $_{i}+\beta_{6}$ Selic $_{t}+\sum_{k=2011}^{2018} \delta_{k}$ Ano $_{k}+\varepsilon_{i}$

\begin{tabular}{|c|c|c|c|c|c|c|}
\hline \multirow{2}{*}{$\begin{array}{c}\text { Característica da } \\
\text { estrutura de propriedade } \\
\text { analisada } \\
\text { Variáveis }\end{array}$} & \multicolumn{2}{|c|}{$\begin{array}{c}\text { Modelo } 1 \\
\text { Concentração de controle } \\
\text { direto }\end{array}$} & \multicolumn{2}{|c|}{$\begin{array}{c}\text { Modelo } 2 \\
\text { Concentração de } \\
\text { propriedade direta }\end{array}$} & \multicolumn{2}{|c|}{$\begin{array}{c}\text { Modelo } 3 \\
\text { Diferença entre direitos } \\
\text { de controle e propriedade } \\
\text { (excesso de controle) }\end{array}$} \\
\hline & Coef. & Sig. & Coef. & Sig. & Coef. & Sig. \\
\hline $\begin{array}{l}\text { Concentração de } \\
\text { controle direto }\end{array}$ & $\begin{array}{c}0,011 \\
(0,005)\end{array}$ & 0,021 & & & & \\
\hline $\begin{array}{l}\text { Concentração de } \\
\text { controle direto^^2 }\end{array}$ & $\begin{array}{l}-0,001 \\
(0,003)\end{array}$ & 0,020 & & & & \\
\hline $\begin{array}{l}\text { Concentração de } \\
\text { propriedade direta }\end{array}$ & & & $\begin{array}{r}-0,0002 \\
(0,001)\end{array}$ & 0,823 & & \\
\hline Excesso de controle & & & & & $\begin{array}{c}0,07 \\
(0,06)\end{array}$ & 0,24 \\
\hline Tamanho & $\begin{array}{c}-0,15 \\
(0,023)\end{array}$ & 0,001 & $\begin{array}{l}-0,15 \\
(0,02)\end{array}$ & 0,001 & $\begin{array}{c}-0,15 \\
(0,023)\end{array}$ & 0,001 \\
\hline Endividamento & $\begin{array}{c}0,66 \\
(0,18)\end{array}$ & 0,001 & $\begin{array}{c}0,67 \\
(0,18)\end{array}$ & 0,001 & $\begin{array}{c}0,64 \\
(0,18)\end{array}$ & 0,001 \\
\hline Garantia real & $\begin{array}{c}0,30 \\
(0,073)\end{array}$ & 0,001 & $\begin{array}{c}0,32 \\
(0,073)\end{array}$ & 0,001 & $\begin{array}{c}0,32 \\
(0,07)\end{array}$ & 0,001 \\
\hline Selic & $\begin{array}{c}2,84 \\
(2,72)\end{array}$ & 0,297 & $\begin{array}{c}3,48 \\
(2,72)\end{array}$ & 0,202 & $\begin{array}{c}3,18 \\
(2,72)\end{array}$ & 0,244 \\
\hline Rentabilidade & $\begin{array}{l}-2,75 \\
(0,66)\end{array}$ & 0,001 & $\begin{array}{l}-2,84 \\
(0,66)\end{array}$ & 0,001 & $\begin{array}{l}-2,80 \\
(0,65)\end{array}$ & 0,001 \\
\hline Constante & $\begin{array}{c}1,96 \\
(0,48)\end{array}$ & 0,001 & $\begin{array}{c}2,07 \\
(0,49)\end{array}$ & 0,001 & $\begin{array}{c}2,13 \\
(0,47)\end{array}$ & 0,001 \\
\hline Efeito fixo do ano & \multicolumn{2}{|c|}{ Sim } & \multicolumn{2}{|c|}{ Sim } & \multicolumn{2}{|c|}{ Sim } \\
\hline Efeito fixo do setor & \multicolumn{2}{|c|}{ Não } & \multicolumn{2}{|c|}{ Não } & \multicolumn{2}{|c|}{ Não } \\
\hline Teste F (F) & 15,0 & 0,00 & 15,6 & 0,000 & 15,7 & 0,00 \\
\hline $\begin{array}{c}\text { Teste de assimetria e } \\
\text { curtose para normalidade } \\
\text { dos resíduos }\end{array}$ & 3,66 & 0,16 & 5,33 & 0,07 & 5,5 & 0,07 \\
\hline $\begin{array}{c}\text { Teste de Breusch-Pagan/ } \\
\text { Cook-Weisberg para } \\
\text { heterocedasticidade }\left(\chi^{2}\right)\end{array}$ & 0,6 & 0,44 & 0,17 & 0,68 & 0,12 & 0,73 \\
\hline $\mathrm{R}^{2}$ & & & & & & \\
\hline $\mathrm{R}^{2}$ ajustado & & & & & & \\
\hline Observações & & & & & & \\
\hline Empresas & & & & & & \\
\hline
\end{tabular}

Nota: os valores apresentados entre parênteses correspondem ao erro padrão dos coeficientes estimados. Os testes de assimetria e curtose, e Breusch-Pagan/Cook-Weisberg apontaram, respectivamente, ausência de problemas de normalidade dos resíduos e heterocedasticidade nos modelos ao nível de confiança de 95\%. Os fatores de inflação da variância apontaram ausência de multicolinearidade, uma vez que o valor máximo, considerando os três modelos, foi inferior a 10. Em função dos modelos não terem apresentados problemas no atendimento aos pressupostos da regressão linear, optouse pela apresentação dos resultados com erros não robustos; no entanto, ao se estimar as mesmas regressões com erros robustos, os resultados se mantiveram estáveis. A significância foi calculada considerando a probabilidade bicaudal. 
Os resultados indicam que a concentração de controle apresenta relação quadrática com o custo da dívida, isto é; até certo ponto, o aumento da concentração de controle é percebido como algo negativo pelos credores, fazendo com que eles exijam uma remuneração maior no fornecimento de capital, porém, à medida que a concentração de controle se torna muito elevada, os credores passam a ver isso como algo benéfico, o que se reflete em um menor spread cobrado no fornecimento de capital.

Um dos possíveis fatores que explicam a redução do custo da dívida à medida que a concentração de controle aumenta é o fato de isso reduzir a probabilidade de mudança de controle da empresa e de suas consequências para os credores. As mudanças de controle acionário tendem a implicar mudanças nas políticas de investimento, financiamento e de dividendos das empresas. Assim, quando as empresas não possuem um controlador definido, há a possibilidade de outros acionistas tomarem o controle da empresa (takeover) e procederem às mudanças indesejáveis pelos credores aos moldes da discussão apresentada por Ashbaugh-Skaife et al. (2006) e Klock et al. (2005). Consequentemente, se as mudanças indesejáveis pelos credores ocorrerem, estes poderiam ter de se sujeitar a assumir riscos desproporcionais ex post àqueles considerados quando da contratação da dívida. Isso reforça a constatação de que a mudança de controle é uma questão sensível para os credores da dívida no Brasil, em linha com o constatado por Konraht (2017), de que credores por debêntures no Brasil incluem, entre os diversos covenants da escritura da dívida, dispositivos que proíbem alterações do controle acionário da empresa durante a vigência da dívida, sem que tal alteração seja aprovada pela assembleia de debenturistas. Vale ressaltar que, como observado na Tabela 2, as empresas da amostra tendem a recorrer, predominantemente, ao capital de terceiros. Para manter o acesso a essa fonte de financiamento, os acionistas controladores podem apresentar uma maior preocupação com a reputação e, consequentemente, com o cumprimento das cláusulas contratuais, similar ao que foi exposto na literatura precedente, por exemplo, em Ashbaugh-Skaife et al. (2006), Anderson et al. (2003) e Byun et al. (2013).

A concentração de propriedade (Modelo 2) não apresenta significância estatística de forma a influenciar variações no spread da dívida. O efeito-alinhamento pode não ser um aspecto considerado pertinente pelos credores no momento da precificação dos títulos de dívida, ao menos no contexto brasileiro, uma vez que os acionistas majoritários tendem a se envolver na administração da empresa. $\mathrm{O}$ argumento de que a diferença entre direitos de controle e de propriedade aumenta o custo da dívida (Modelo 3) também não apresentou significância estatística. Na amostra analisada, a mediana das variáveis de concentração de propriedade e de concentração de controle não são expressivamente diferentes, embora o coeficiente de variação demonstre que as empresas são razoavelmente heterogêneas. Aparentemente, isto contraria os resultados relatados por Konraht et al. (2016) para o contexto brasileiro. Contudo, devese atentar ao fato de que esses autores utilizam como variável para custo da dívida a razão entre despesas financeiras e o passivo oneroso. Os resultados apresentados na Tabela 3 se referem ao custo da dívida enquanto custo de emissão de debêntures. As especificidades dos contratos de debêntures e o uso desses contratos pelas empresas podem interferir nos incentivos, tantos dos acionistas como dos credores.

Por fim, foram realizados testes adicionais reestimando as mesmas regressões dos modelos 1, 2 e 3, com a segmentação da amostra por modalidade de emissão de debênture: aberta ao público em geral e esforços restritos. Além desse teste, foi testada a substituição da variável diferença entre controle e propriedade, calculada a partir de Cronqvist e Nilsson (2003), por outras medidas de diferença entre direitos de votos e propriedade: (a) diferença (subtração) entre o percentual de controle e o percentual de propriedade; e, (b) variável binária identificando os casos em que o percentual de controle excede o percentual de propriedade. Os resultados encontrados nesses testes foram consistentes com aqueles apresentados na Tabela 4, não alterando as constatações da análise. 


\section{Considerações finais}

Este artigo apresenta evidências acerca da relação entre a estrutura de propriedade e o custo da dívida, especificamente, em relação à captação de dívida via debêntures no Brasil. Duas hipóteses foram formuladas tendo como base as previsões teóricas acerca da magnitude dos custos de agência entre acionistas e credores. A primeira hipótese prevê que o excesso de controle aumentaria o custo da dívida, pressupondo-se que os custos da dívida aumentam à medida que os conflitos de interesse entre proprietários e credores também aumentam. Contudo, os resultados apresentados não confirmam que isto ocorre para a amostra analisada. Possivelmente, os credores têm conseguido, por exemplo, incorporar o risco de variância dos fluxos de caixa futuros nas cláusulas restritivas e nas garantias exigidas na emissão de debêntures, de forma a tornar as taxas de juros mais adequadas. Assim, o alinhamento entre proprietários e gestores e entre proprietários pode não ser a preocupação central dos credores.

A segunda hipótese previa que a concentração do direito de propriedade direta (controle) reduziria o custo da dívida. Para a concentração de controle direto os resultados foram positivos e significativos; ainda, a relação quadrática mostra que à medida que a concentração de controle aumenta essa relação se torna negativa. Por isso, interpreta-se que, até certo ponto, o aumento da concentração de controle é percebido como algo negativo pelos credores, fazendo com que eles exijam uma remuneração maior no fornecimento de capital; mas à medida que a concentração de controle se torna bastante elevada, os credores passam a ver isso como algo benéfico, o que se reflete em um menor spread cobrado no fornecimento de capital via emissão de debêntures. Como os resultados não foram significativos para a concentração de propriedade direta interpreta-se que, diante da configuração particular da propriedade no Brasil, os credores tendem a atribuir maior relevância ao risco de mudança do controle do que aos benefícios gerados pelo alinhamento de interesses vindos da concentração de propriedade.

Os resultados mostram que a percepção dos debenturistas (detentores da dívida) sobre o efeito do custo da dívida no valor da companhia difere daquele dos acionistas outsiders, ou seja, a questão do efeito alinhamento e do efeito entrincheiramento. No Brasil, os acionistas majoritários são, frequentemente, os administradores da empresa ou mantém uma relação muito estreita com a administração da empresa. Talvez, para os credores seja mais pertinente uma decisão abaixo do ideal do que uma mudança de risco. Por exemplo, como exposto por Jiraporn et al. (2013), se a administração agir preponderantemente em nome dos acionistas, pode ser que passe a subinvestir em projeto de valor presente líquido positivo, porque o benefício se acumularia principalmente para os detentores da dívida.

Por fim, cabe destacar que, dadas as decisões metodológicas adotadas para a operacionalização da pesquisa, os resultados apresentam algumas limitações. Primeiramente, os resultados obtidos limitamse à amostra de séries de debêntures analisadas, uma vez que a análise do custo da dívida incluiu apenas as séries de debêntures que utilizam a remuneração no formato de taxa DI mais uma taxa fixa percentual, conforme detalhado na seção 3. Cada contrato de emissão de debêntures tende a apresentar muitas especificidades, as quais não foram tratadas na análise dos dados agrupados. Outra limitação é que a estrutura de propriedade e controle pode também ser analisada sob outras perspectivas, tal como pela abordagem da identidade do acionista controlador, em que a literatura aponta haver diferença na percepção de valor da firma quando o controle é individual ou familiar, estatal, institucional, nacional ou estrangeiro, por exemplo. Além disso, como a análise é feita para a participação acionária direta, pesquisas futuras poderiam considerar as participações acionárias piramidais, ou seja, as participações indiretas que tendem a demonstrar concentração do controle onde aparentemente não haveria. Por fim, a análise não é conduzida para outras formas de financiamento das empresas, as quais são utilizadas, por vezes, concomitantemente ao financiamento por debêntures, como empréstimos bancários e aqueles intragrupo. Os resultados desta pesquisa podem ser refinados ainda mais, levando em consideração, simultaneamente, o custo de outras fontes de financiamento, a identidade do acionista controlador e, até mesmo, características do conselho de administração. 


\section{Referências}

Aldrighi, D. M. (2014). Concentração da propriedade do capital e controle das empresas no Brasil. Anais. Sociedade Brasileira de Finanças. Recuperado de http://www.sbfin.org.br/site/Encontros/2014/art igosaceitos?action $=$ AttachFile $\&$ do $=$ get $\&$ target $=I D 4663 . p d f$

Aldrighi, D. M., \& Mazzer Neto, R. (2007). Evidências sobre as estruturas de propriedade de capital e de voto das empresas de capital aberto no Brasil. Revista Brasileira de Economia, 61(2), pp. 129152. Recuperado de https://www.scielo.br/pdf/rbe/v61n2/a01v61n2.pdf doi: 10.1590/S003471402007000200001 .

Aldrighi, D. M., \& Postali, F. A. S. (2011). Propriedade piramidal das empresas no Brasil. Economia: Revista da ANPEC, 12( 1), pp. 27-48. Recuperado de http://www.anpec.org.br/revista/vol12/ vol12n1p27_48.pdf

ANBIMA (2020). Boletim de Mercado de Capitais 02/2020: renda variável representa 60\% do volume captado em fevereiro. Recuperado de: https://www.anbima.com.br/pt_br/informar/relatorios/ mercado-de-capitais/boletim-de-mercado-de-capitais/renda-variavel-representa-60-do-volumecaptado-em-fevereiro.htm

Anderson, R. C., Mansi, S. A., \& Reeb, D. M. (2003). Founding family ownership and the agency cost of debt. Journal of Financial Economics, 68(2), pp. 263-285. doi: 10.1016/S0304-405X(03)00067-9.

Andrade, L. P., Bressan, A. A., \& Iquiapaza, R. A. (2014). Estrutura piramidal de controle, emissão de duas classes de ações e desempenho financeiro das empresas brasileiras. Revista Brasileira de Finanças, 12(4), pp. 555-595. doi: 10.12660/rbfin.v12n4.2014.24499

Ashbaugh-Skaife, H., Collins, D. W., \& LaFond, R. (2006). The effects of corporate governance on firms' credit ratings. Journal of Accounting and Economics, 42(1-2), pp. 203-243. doi: 10.1016/j. jacceco.2006.02.003.

Aslan, H., \& Kumar, P. (2012). Strategic ownership structure and the cost of debt. The Review of Financial Studies, 25(7), pp. 2257-2299. doi: 10.1093/rfs/hhs062.

Barros, C. M. E., Silva, P. Y. C., \& Voese, S. B. (2015). Relação entre o custo da dívida de financiamentos e governança corporativa no Brasil. Contabilidade, Gestão e Governança, 18(2), pp. 7-26. Recuperado de https://www.revistacgg.org/contabil/article/view/641/pdf

Bebchuk, L., Kraakman, R., \& Triantis, G., 2000. Stock pyramids, cross ownership, dual-class equity: The creation and agency costs of separating control from cash flow rights. In: Morck, R.K. (Ed.), Concentrated corporate ownership. University of Chicago Press, Chicago, pp. 295-318. Recuperado de https://www.nber.org/papers/w6951.pdf doi: 10.3386/w6951.

Bharath, S. T., Sunder, J., \& Sunder, S. V. (2008). Accounting quality and debt contracting. The Accounting Review, 83(1), pp. 1-28. doi: 10.2308/accr.2008.83.1.1

Bortolon, P. M. (2013). Por que as empresas brasileiras adotam estruturas piramidais de controle. BASE - Revista de Administração e Contabilidade da UNISINOS, 10(1), pp. 2-18. Recuperado de https:// www.researchgate.net/publication/314641777_Por_que_as_empresas_brasileiras_adotam_ estruturas_piramidais_de_controle doi: 10.4013/base.2013.101.01

Bortolon, P. M., \& Leal, R. P. C. (2014). Dual-class unifications and corporate governance in Brazil. Emerging Markets Review, 20, pp. 89- 108. Recuperado de https://www.sciencedirect.com/science/ article/abs/pii/S1566014114000375?via\%3Dihub doi: 10.1016/j.ememar.2014.06.003 
Boubakri, N., \& Ghouma, H. (2010). Control/ownership structure, creditor rights protection, and the cost of debt financing: International evidence. Journal of Banking and Finance, 34(10), pp. 2481-2499. Recuperado de https://www.sciencedirect.com/science/article/abs/pii/S0378426610001329 doi: 10.1016/j.jbankfin.2010.04.006.

Byun, H.-Y., Choi, S., Hwang, L.-S. S., \& Kim, R. G. (2013). Business group affiliation, ownership structure, and the cost of debt. Journal of Corporate Finance, 23, pp. 311-331. Recuperado de https://pdfs.semanticscholar.org/7a02/cb5ed39bf6955ba70d1d1c5cd8f77992aaf9.pdf? $\mathrm{ga}=2.252555726 .63341923 .1588187574-401073071.1581106557$ doi: 10.1016/j.jcorpfin.2013.09.003 .

Caixe, D. F., \& Krauter, E. (2013). A influência da estrutura de propriedade e controle sobre o valor de mercado corporativo no Brasil. Revista Contabilidade \& Finanças, 24, pp. 142-153. Recuperado de http://www.revistas.usp.br/rcf/article/view/78826/82891 doi: 10.1590/S1519-70772013000200005.

Céspedes, J., González, M., \& Manzano, C. M. (2010). Ownership and capital structure in Latin America. Journal of Business Research, 63(3), pp. 248-254. Recuperado de https://www.sciencedirect. com/science/article/abs/pii/S014829630900068X?via\%3Dihub\#aep-abstract-id5 doi: 10.1016/j. jbusres.2009.03.010

Claessens, S., Djankov, S., Fan, J. P. H., \& Lang, L. H. P. (2002). Disentangling the incentive and entrenchment effects of large shareholdings. The Journal of Finance, 57(6), pp. 2741-2771. Recuperado de https:// onlinelibrary.wiley.com/doi/full/10.1111/1540-6261.00511 doi: 10.1111/1540-6261.00511.

Comissão de Valores Mobiliários (2009). Instrução Normativa no 476/09. Dispõe sobre as ofertas públicas de valores mobiliários distribuídas com esforços restritos e a negociação desses valores mobiliários nos mercados regulamentados. Recuperado de: http://www.cvm.gov.br/legislacao/instrucoes/ inst476.html

Crisóstomo, V. L., Brandão, I. de F., \& López-Iturriaga, F. J. (2020). Large shareholders' power and the quality of corporate governance: an analysis of Brazilian firms. Research in International Business and Finance, 51, pp. 1-15. Recuperado de https://www.sciencedirect.com/science/article/pii/ S0275531918310997. doi: 10.1016/j.ribaf.2019.101076

Cronqvist, H., \& Nilsson, M. (2003). Agency costs of controlling minority shareholders. The Journal of Financial and Quantitative Analysis, 38(4), pp. 695-719. doi: 10.2307/4126740.

Fonseca, C. V. C., \& Silveira, R. L. F. (2016). Governança corporativa e custo de capital de terceiros: Evidências entre empresas brasileiras de capital aberto. REAd. Revista Eletrônica de Administração, 22(1), pp. 106-133. Recuperado de https://www.scielo.br/scielo.php?script=sci_arttext\&pid=S141323112016000100106\&lng=en\&nrm=iso\&tlng=pt. doi: 10.1590/1413-2311.016162016.62739

Grillo, F. F., Reina, D., Bortolon, P. M., \& Sarlo Neto, A. (2017). Influência da presença familiar no controle, gestão e conselho de administração sobre a relevância e a tempestividade das informações contábeis. Revista Universo Contábil, 13(1), pp. 85-105. Recuperado de https://proxy.furb.br/ojs/index.php/ universocontabil/article/view/5885 doi: 10.4270/RUC.2017105.

Guedhami, O., \& Mishra, D. (2009). Excess Control, Corporate Governance and Implied Cost of Equity: International Evidence. The Financial Review, 44(4), pp. 489-524. Recuperado de https://onlinelibrary.wiley.com/doi/abs/10.1111/j.1540-6288.2009.00227.x doi: 10.1111/j.15406288.2009.00227.x

Jensen, M. C. (1986). Agency costs of free cash flow, corporate finance, and takeovers. The American Economic Review, 76(2), pp. 323-329. doi: 10.2139/ssrn.99580 
Jensen, M. C., \& Meckling, W. H. (1976). Theory of the firm: Managerial behavior, agency costs and ownership structure. Journal of Financial Economics, 3(4), pp. 305-360. Recuperado de https:// uclafinance.typepad.com/main/files/jensen_76.pdf doi: 10.1016/0304-405X(76)90026-X.

Jiraporn, P., Chintrakarn, P., Kim, J. C., \& Liu, Y. (2013). Exploring the agency cost of debt: Evidence from the ISS Governance Standards. Journal of Financial Services Research, 44(2), pp. 205-227. Recuperado de https://link.springer.com/article/10.1007/s10693-012-0142-2 doi: 10.1007/s10693012-0142-2.

La Porta, R., Lopez-de-Silanes, F., Shleifer, A., \& Vishny, R. (2000). Investor protection and corporate governance. Journal of Financial Economics, 58(1-2), pp. 3-27. https://scholar.harvard.edu/files/ shleifer/files/ip_corpgov.pdf Recuperado de doi: 10.1016/S0304-405X(00)00065-9

Klock, M., Mansi, S., \& Maxwell, W. (2005). Does corporate governance matter to bondholders. Journal of Financial and Quantitative Analysis, 40, pp. 693-720. doi: 10.1017/S0022109000001940.

Konraht, J. M. (2017). Determinantes da utilização dos covenants contábeis nas debêntures emitidas pelas empresas listadas na BMઐFBOVESPA (Dissertação de mestrado). Universidade Federal de Santa Catarina, Florianópolis, SC, Brasil. Recuperado de https://repositorio.ufsc.br/bitstream/ handle/123456789/178713/347921.pdf?sequence $=1$ \&isAllowed $=\mathrm{y}$

Konraht, J. M., Camargo, R. V. W., \& Vicente, E. F. R. (2016). Excesso de controle acionário: um estudo do seu reflexo sobre o custo da dívida das empresas brasileiras de capital aberto. Enfoque: Reflexão Contábil, 35(2), pp. 105-121. Recuperado de http://periodicos.uem.br/ojs/index.php/Enfoque/ article/view/31371/pdf doi: 10.4025/enfoque.v35i2.31371.

Konraht, J. M., \& Soares, R. O. (2020). O Duplo Papel dos Covenants Contábeis na Captação de Dívida no Brasil. Revista Brasileira de Gestão de Negócios, 22(1), pp. 183-199. Recuperado de https://www. scielo.br/pdf/rbgn/v22n1/pt_1983-0807-rbgn-22-01-183.pdfdoi: 10.7819/rbgn.v22i1.4041

Lin, C., Ma, Y., Malatesta, P., \& Xuan, Y. (2011). Ownership structure and the cost of corporate borrowing. Journal of Financial Economics, 100(1), pp. 1-23. Recuperado de https://www.sciencedirect.com/ science/article/abs/pii/S0304405X10002485doi: 10.1016/j.jineco.2010.10.012.

Lugo, S. (2019). Insider ownership and the cost of debt capital: Evidence from bank loans. International Review of Financial Analysis, 63(5), pp. 357-368. Recuperado de https://www.sciencedirect.com/ science/article/abs/pii/S1057521916301934?via\%3Dihub doi: 10.1016/j.irfa.2016.12.007.

Myers, S. C. (1977). Determinants of corporate borrowing. Journal of Financial Economics, 5(2), pp. 147175. Recuperado de https://www.sciencedirect.com/science/article/abs/pii/0304405X77900150 doi: 10.1016/0304-405X(77)90015-0.

Okimura, R. T., Silveira, A. D. M., \& Rocha, K. C. (2007). Estrutura de Propriedade e Desempenho Corporativo no Brasil. Revista de Administração Contemporânea, 1(1), pp. 119-135. Recuperado de http://www.spell.org.br/documentos/ver/31027/estrutura-de-propriedade-e-desempenhocorporativo-no-brasil

Sanchez-Ballesta, J. P., \& García-Meca, E. (2011). Ownership structure and the cost of debt. European Accounting Review, 20(2), pp. 389-416. Recuperado de https://www.researchgate. net/publication/227613958_Ownership_Structure_and_the_Cost_of_Debtdoi: $10.1080 / 09638180903487834$

Sheng, H. H., \& Saito, R. (2005). Determinantes de spread das debêntures no mercado brasileiro. Revista de Administração, 40(2), pp. 193-205 Recuperado de http://rausp.usp.br/wp-content/uploads/files/ V4002193.pdf. 
Shleifer, A., \& Vishny, R. (1997). A survey of corporate governance. Journal of Finance, 52, pp. 737 783. Recuperado de https://scholar.harvard.edu/files/shleifer/files/surveycorpgov.pdfdoi: 10.1111/ j.1540-6261.1997.tb04820.x

Silva, A. L. C. (2004). Governança corporativa, valor, alavancagem e política de dividendos das empresas brasileiras. Revista de Administração, 39(4), pp. 348-361. Recuperado de http://rausp.usp.br/wpcontent/uploads/files/V3904348a361.pdf

Silva, E. D. S., Santos, J. F. D., \& Almeida, M. A. (2012). Os efeitos dos mecanismos de governança corporativa sobre os ratings de crédito das debêntures. Revista de Negócios, 17(3), pp. 80-93. Recuperado de https://proxy.furb.br/ojs/index.php/rn/article/view/3106/2085doi: 10.7867/1980-4431.2012v17n 3p80-93

Silveira, A. M., Barros, L. A. B., \& Famá, R. (2008). Atributos corporativos e concentração acionária no Brasil. Revista de Administração de Empresas, 48(2), pp. 51-66. Recuperado de https://rae. fgv.br/sites/rae.fgv.br/files/artigos/10.1590_S0034-75902008000200005.pdf doi: 10.1590/S003475902008000200005 .

Steijvers, T., \& Voordeckers, W. (2009). Private family ownership and the agency costs of debt. Family Business Review, 22(4), pp. 333-346.Recuperado de http://citeseerx.ist.psu.edu/viewdoc/downloa $\mathrm{d}$ ?doi=10.1.1.1018.7572\&rep=rep1\&type=pdf doi: 10.1177/0894486509338291. 